\title{
Greener Solution to Waste Corn Stalks and Shortage of Asphalt Resource: Hydrochar Produced by Hydrothermal Carbonization as a Novel Performance Enhancer for Asphalt Binder
}

\author{
Xiaoming $\mathrm{Wu}(\mathbb{D}$ and Chichun $\mathrm{Hu}$ * \\ School of Civil Engineering and Transportation, South China University of Technology, \\ Guangzhou 510641, China; ctxmwu@mail.scut.edu.cn \\ * Correspondence: cthu@scut.edu.cn; Tel.: +86-138-2604-0612
}

check for updates

Citation: Wu, X.; Hu, C. Greener Solution to Waste Corn Stalks and Shortage of Asphalt Resource:

Hydrochar Produced by

Hydrothermal Carbonization as a Novel Performance Enhancer for Asphalt Binder. Materials 2021, 14, 1427. https://doi.org/10.3390/ ma14061427

Academic Editor: Vilma Ducman

Received: 22 February 2021

Accepted: 11 March 2021

Published: 15 March 2021

Publisher's Note: MDPI stays neutral with regard to jurisdictional claims in published maps and institutional affiliations.

Copyright: (c) 2021 by the authors. Licensee MDPI, Basel, Switzerland. This article is an open access article distributed under the terms and conditions of the Creative Commons Attribution (CC BY) license (https:/ / creativecommons.org/licenses/by/ $4.0 /)$.
Abstract: Utilization of waste corn stalks (CS) has seized extensive attention due to high annual output and hazardous impact of piling aside or direct combustion on environment. However, previously there has been a lot of emphasis on improvement of its energy efficiency as solid fuel while limited investigations are available which explore the possibility of applying corn stalks as performance enhancer in asphalt binder. The purpose of this study is to examine the potential of employing hydrochar as modifiers in asphalt binder by a series of experimental tests. In this study, two hydrochar were produced from corn stalks by a novel process called hydrothermal carbonization at a different reaction temperature. The two hydrochar and their responding hydrochar-modified asphalt (HCMA) were tested by chemical and rheological tests. Chemical analysis detected the interaction between hydrochar and binder factions, resulting in poor compatibility but satisfying anti-aging property. Even though hydrochar increased the viscosity of bitumen, implying worse workability, and caused poor storage stability, ameliorated performance of asphalt binder at high temperature by incorporating hydrochar was verified by various criteria such as higher performance grade $(\mathrm{PG})$ failure temperature and lower non-recoverable creep compliance $\left(\mathrm{Jnr}_{\mathrm{nr}}\right)$. Moreover, higher reaction temperature makes hydrochar's particles smaller and more homogeneous, which results in slightly lower enhanced high temperature performance, more satisfying workability, better storage stability, and greater anti-aging effect of hydrochar-modified asphalt. Eventually, this study provided a promising win-win solution to environment problems concerning corn stalk treatment and shortage of asphalt binder. Further exploration of methods to improve HCMA's storage stability, real-scale corroboration on trial section and life cycle assessment of asphalt pavement containing hydrochar modifiers will be followed in the future.

Keywords: corn stalk; modified binder; anti-aging effect; rheological tests; chemical analysis

\section{Introduction}

As more attention has been drawn on sustainable development, concern of the environmental problem induced by the abundant discarded corn stalks (CS) produced from agricultural industry is growing rapidly, which is more severe in China because of its high annual output of corn stalks (about 250 million tons per year) and poor efficiency of waste utilization [1]. Traditional treatment of corn stalks is combusting them directly as a kind of fuel, whose energy efficiency is low and consequently causes large amounts of $\mathrm{CO}, \mathrm{CO}_{2}$ and $\mathrm{NO}_{2}$ emissions leading to increase in diseases [2]. More commonly, farmers would rather stack them on the field than try to utilize them; however, this accidentally results in eutrophication, which is hazardous to farmland [3]. In other words, great benefits will be achieved if proper treatment is undertaken for corn stalks. Many efforts have been made to develop an environmentally friendly solution to waste corn stalks, consisting of hydrothermal process, pyrolysis and hydrothermal carbonization [4,5]. Not only economic but also environment-friendly processes for corn stalks are drawing extensive attention. 
Flexible pavement, namely, asphalt pavement, has taken the first place to be paved in highway because of its exclusive advantages such as improved smoothness, low driving noise, and accessible maintenance. As large-scale pavement construction has been undertaken from the 21st century, especially in developing countries, demand for asphalt binder, a by-product from the petroleum industry, has consequently risen at an unbelievable speed. Similar to other unsustainable resources, there is a contradiction between the growing demand for asphalt binder, and its decreasing annual production restricted by local environmental protection policy [5]. What is more, the above contradiction leads to a higher price of asphalt binder. Great efforts have been made to cut down the consumption of asphalt binder by exploring alternative binder, as well as reducing binder content in asphalt mixtures by modification technique. For the sake of heightening mechanical properties of asphalt pavement, such as rutting resistance at high temperature, fatigue resistance at intermediate temperature, and fracture resistance at low temperature, numerous materials have been developed as modifiers, among which styrene-butadiene-styrene conjugated copolymer [6] is the most effective one for its improvement in overall performance of asphalt pavements.

In terms of biomass processes, several representative studies should be mentioned. Firstly, Dhasmana et al. employed a hydrothermal liquefaction technique to convert biomass such as spirulina algae, swine manure, and nanoalgae into bio-binder, which exhibited distinctly different rheological and chemical properties compared to petroleum binder [7]. As supplement, Fini et al. put forward that bio-binder produced from swine manure could improve asphalt binder's low temperature performance while cutting down the construction expense of flexible pavement by partial replacement [8]. However, Yang et al. drew a conclusion that the compatibility with asphalt binder would decrease if a greater fraction of bio-binder was incorporated [9]. Moreover, Walters et al. affirmed that incorporating bio-char, acquired by a filtration procedure after bio-binder was produced, could improve asphalt rheological behavior and aging susceptibility [10]. Additionally, reduced temperature susceptibility and better rutting, cracking and moist resistance of bio-charmodified asphalt mixture were detected [11,12]. Furthermore, Zhang et al. appraised the effect of bio-char particle size on the rheological characteristics of binder and put forward that smaller-sized bio-char particles could lead to superior rutting resistance and anti-aging properties due to the porous structure and rough surface [13]. Recently, Zhou and Adhikari discovered that the flow-induced crystallization could be improved by adding bio-char [14]. Differently, Araújo et al. developed a polyester obtained from sugarcane bagasse-derived polyol through pyrolysis, which was polymerized with pyromellitic anhydride, as new additives for binder [15]. There are several studies investigating the potential of applying ashes from biomass combustion as aggregate fillers for asphalt mixtures [16-18], antioxidant [19] or performance enhancer [20] for asphalt binder. Specifically, Chen et al. invented a preparation method of corn stalk fiber involving sodium hydroxide [1] and evaluated the effect on binder [21].

In the past few years, biomass like corn stalk has been regarded as kind of fuel in the agricultural industry when processed. It is commonly thought that the focus is to generate highly energy-efficient renewable fuel resources using biomass. Towards this research direction, hydrothermal carbonization stands out from other thermal chemical process due to its improvement of upgrading the fuel properties [22] and dewatering of wet-basis biomass [23]. However, hydrochar produced from hydrothermal carbonization using biomass such as corn stalk seems not suitable for biofuel production [11]. On the contrary, utilizing hydrochar as binder modifiers instead of solid fuel seems more reasonable. As proof, Chen et al. made worthful achievement by exploring an innovative way of converting corn stalks to fiber material [1] and performance evaluation of asphalt modified by corn stalk fiber [21]. What is more, Bao et al. investigated the chemical composition and rheological properties of bio-asphalt, the residue from corn waste processed through acidification and polymerization [24]. In addition, Dong et al. examined the effects of bio-binder made from corn on rheological properties of asphalt binder and performance of 
mixture [25]. Despite some valuable studies above related to waste corn material having been conducted, limited studies seriously consider the thought of exploiting hydrochar and draw attention from stakeholders in the asphalt industry. It is of immense benefit both environmentally and economically if corn stalks are treated as associated with asphalt industry. Waste corn stalks can be converted to hydrochar, which is an innovative method to consume corn stalks. Moreover, due to the properties of hydrochar, it has great potential to be employed as asphalt modifier. Hence, the purpose of this study is to comprehensively examine the potential of employing hydrochar in asphalt binder as modifiers by a series of experimental tests. Emphasis was placed on the mechanism how reaction temperature affects the properties of hydrochar and the effect on hydrochar-modified asphalt by means of chemical analysis and rheological tests. Through a novel method called hydrothermal carbonization, waste corn stalks from the agricultural industry could be converted to hydrochar, which serves as an innovative asphalt modifier in pavement engineering. Mountains of waste corn stalks could be consumed, while performance of asphalt pavement could be improved, which would consequently cut down the enormous cost of asphalt material. It is anticipated that this study would provide a win-win solution to environment problems concerning corn stalks treatment and shortage of asphalt binder.

\section{Materials and Methods}

2.1. Materials and Sample Preparation

\subsubsection{Materials}

The Pen60/70 raw bitumen obtained from Shell Co. Ltd. (Foshan, Guangdong, China), which is commonly applied in south China was selected as the base bitumen. The corn stalks which were later transformed into hydrochar were obtained from Henan province in China. Raw corn stalks were mechanically pulverized to 10 mesh and positioned in an oven at $80^{\circ} \mathrm{C}$ overnight.

\subsubsection{Preparation of Hydrochar}

For the purpose of manufacturing hydrochar, $500 \mathrm{~g}$ pulverized corn stalks were mixed with $7.5 \mathrm{~L}$ deionized water in a $10 \mathrm{~L}$ Hastelloy reaction vessel. The mixture was heated to $180^{\circ} \mathrm{C}$ and $210^{\circ} \mathrm{C}$, respectively, for different types of hydrochar (HA, HB are abbreviations for hydrochar A, hydrochar B) and kept at this temperature for an hour. After cooling, the product was separated by sifting through filter paper. Residual moisture was removed in an oven at $80{ }^{\circ} \mathrm{C}$. On account of different reaction temperature, $\mathrm{HA}$ and $\mathrm{HB}$ have similar physical shapes observed by eye (Figure 1a,b). Further observation of HA and HB (Figure 1c,d) on the fluorescence microscope (FM) leads to a conclusion that HA has more interconnected fiber structure which could be beneficial to the high temperature performance of modified bitumen.

\subsubsection{Preparation of Hydrochar-Modified Asphalt (HCMA)}

The hydrochar-modified asphalt was prepared by wet process, including manually stirring hydrochar modifiers and base bitumen with a glass rod for $5 \mathrm{~min}$ and then blending them with a mixer at a speed of $2000 \mathrm{rpm}$ for $30 \mathrm{~min}$, at $(165 \pm 5)^{\circ} \mathrm{C}$. It was noted that swelling would happen when hydrochar was added into the hot asphalt, hence, hydrochar modifiers should be slowly poured into the base bitumen. The material dosages and mixing conditions were chosen on the basis of previous study [26]. In terms of mixing conditions, low shearing speed $(2000 \mathrm{rpm})$ and shorter shearing time $(30 \mathrm{~min})$ are adequate for modifiers such as hydrochar which is produced from high temperature and pressure. Moreover, it consumes less energy which corresponds to the goal of environmental protection. The two prepared hydrochar-modified asphalt were called HAMA (HA-modified asphalt) and HBMA (HB-modified asphalt) for short, respectively. A batch of approximately $500 \mathrm{~g}$ hydrochar-modified asphalt could be manufactured after a standard preparation process. Figure 2 illustrates the preparation process of the hydrochar-modified asphalt from the stage of crushed corn stalks. 


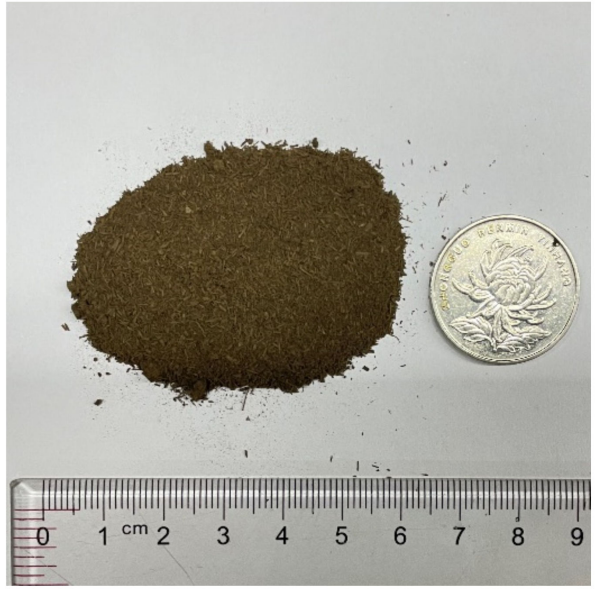

(a)

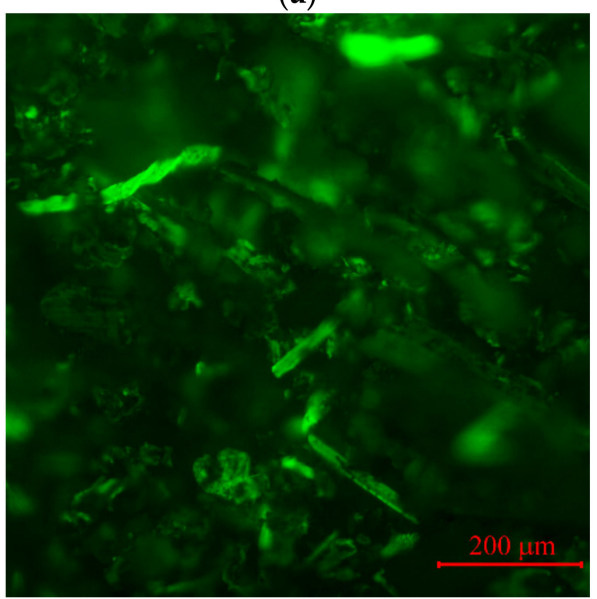

(c)

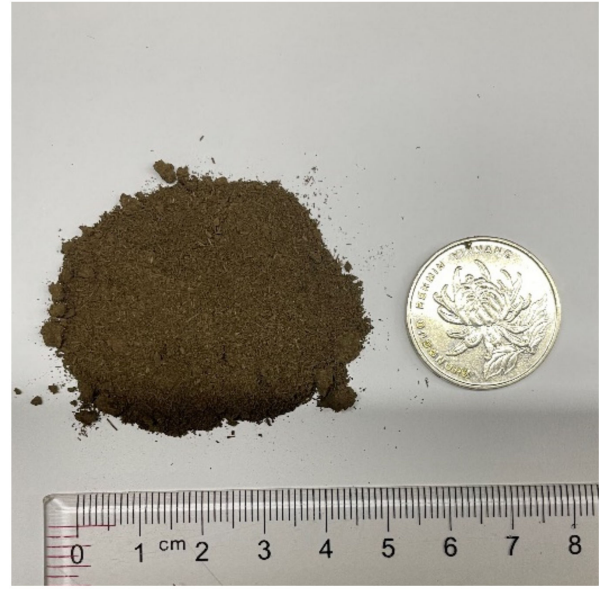

(b)

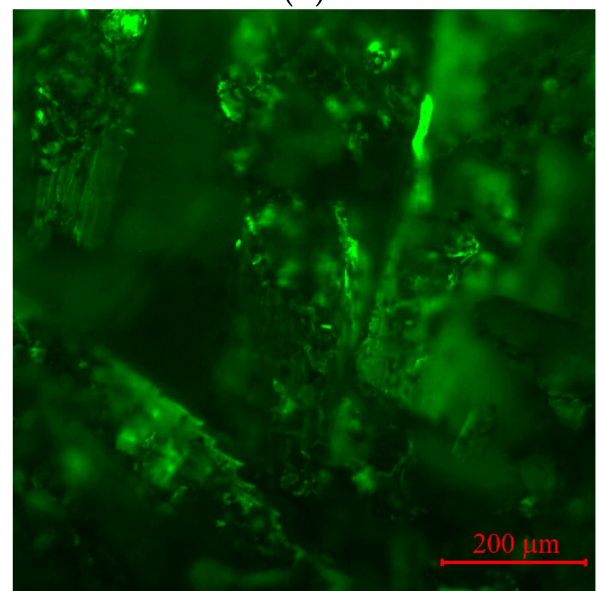

(d)

Figure 1. Hydrochar modifiers: (a) hydrochar A (HA) and (b) hydrochar B (HB); FM images of (c) HA and (d) HB.

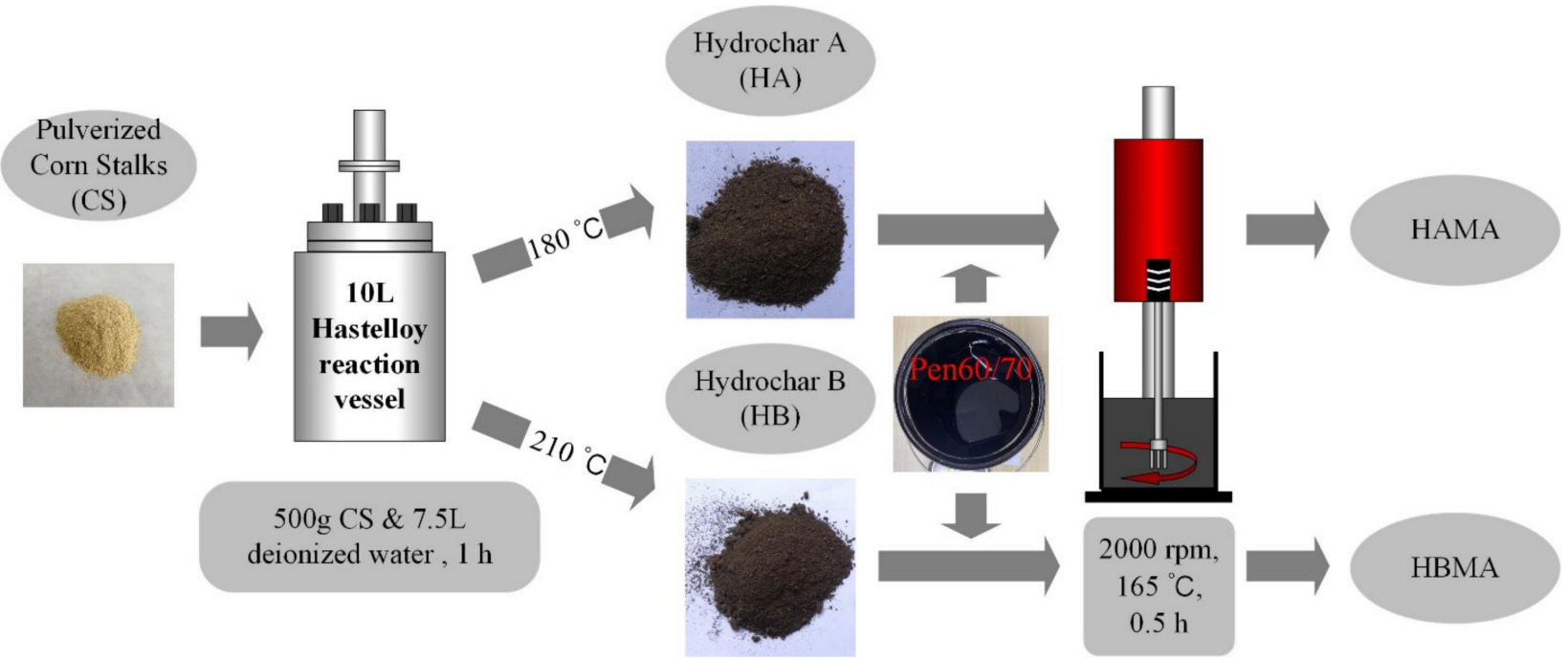

Figure 2. Preparation of hydrochar-modified asphalt (HCMA). 


\subsection{Testing Program}

The experimental scheme of this study is summarized in Table 1.

Table 1. Experimental scheme.

\begin{tabular}{|c|c|c|c|}
\hline Performance & Tests & Simulated Condition & Standards \\
\hline \multirow{2}{*}{ Basic characteristics } & Penetration & \multirow{2}{*}{ unaged } & AASHTO T 49 \\
\hline & Softening point & & AASHTO T 53 \\
\hline Workability & Rotational viscosity & unaged & AASHTO T 316 \\
\hline Separation tendency & Storage stability & storage & ASTM D 5892, D 7173 \\
\hline \multirow{2}{*}{ High temperature performance } & Temperature sweep & unaged, short-term-aged & AASHTO M 320 \\
\hline & MSCR $^{a}$ & short-term-aged & AASHTO T 350, M332 \\
\hline Overall rheological behavior & Frequency sweep & unaged & $\mathrm{N} / \mathrm{A}$ \\
\hline Molecular weight distribution & Gel Permeation Chromatography (GPC) & unaged & $\mathrm{N} / \mathrm{A}$ \\
\hline Interaction identification & Fourier-Transform Infrared & unaged & $\mathrm{N} / \mathrm{A}$ \\
\hline Anti-aging evaluation & Spectroscopy (FTIR) & unaged, short-term-aged & $\mathrm{N} / \mathrm{A}$ \\
\hline
\end{tabular}

${ }^{\text {a }}$ MSCR, multiple stress creep recovery.

\subsubsection{Penetration and Softening Point}

The fundamental properties of test bitumen were appraised by two traditional tests, namely, penetration [27] and softening point tests [28]. As an index to evaluate the hardness and consistency of test bitumen, penetration is defined by the depth $(0.1 \mathrm{~mm})$ of a standard needle $(100 \pm 0.1 \mathrm{~g})$ sinking into the test bitumen sample for a specified loading time $(5 \mathrm{~s})$, at a selected temperature $\left(25^{\circ} \mathrm{C}\right)$. Considered as an indicator to characterize the high temperature property of bitumen, softening point is determined by the temperature at which a steel ball ( $3.5 \mathrm{~g})$ positioned on the top surface of a bitumen sample reaches a distance of $25.4 \mathrm{~mm}$ under gravity. Bitumen samples were prepared by being filled in rings and then placed in a water bath at $5{ }^{\circ} \mathrm{C}$ for at least $30 \mathrm{~min}$. The temperature of the water bath was increased at a fixed rate of $5^{\circ} \mathrm{C} / \mathrm{min}$ during the softening point test.

\subsubsection{Rotational Viscosity}

The workability of bitumen samples was evaluated by their rotational viscosity at $135^{\circ} \mathrm{C}, 150^{\circ} \mathrm{C}$ and $165^{\circ} \mathrm{C}$, respectively [29]. RV tests were conducted with a Brookfield viscometer (AMETEK Brookfield Company, Middleboro, MA, USA). After preliminary trials, 27\# spindle and testing temperature $\left(135^{\circ} \mathrm{C}, 150^{\circ} \mathrm{C}\right.$ and $\left.165^{\circ} \mathrm{C}\right)$ were selected.

\subsubsection{Storage Stability}

The heterogeneity of binder stored in the container is one of the major concerns for construction quality. Considered as a crucial parameter for pavement construction, storage stability determines the separation tendency of asphalt binder after high-temperature storage. The ASTM D 7173 [30] procedure was referred to imitate the storage condition of modified binder (being stored at high temperature). The following steps describe the experimental procedure: (1) filling an aluminum tube (with $25 \mathrm{~mm}$ and $140 \mathrm{~mm}$ length) with modified binder which was heated to reduce its viscosity in advance; (2) enclosing the tube and placing it vertically in air heater at $163{ }^{\circ} \mathrm{C}$ for $(48 \pm 1) \mathrm{h}$; (3) transferring the tube from the air heater to a freezer at $5{ }^{\circ} \mathrm{C}$; and (4) segregating the tube horizontally into three uniform parts and keeping the top and bottom portions for the softening point test while the middle one was discarded. Difference in softening point was employed to evaluate the storage stability of asphalt binder.

\subsubsection{Temperature Sweep and Multiple Stress Creep Recovery (MSCR)}

To determine the performance grade (PG) of test bitumen, the dynamic shear rheometer (DSR, Malvern Kinexus Lab+, Malvern Panalytical, Malvern, UK) test [31] was employed in this study. The $25 \mathrm{~mm}$ parallel plate geometry was selected, setting a $1 \mathrm{~mm}$ 
spacing for both the temperature sweep test and the multiple stress creep recovery (MSCR) test. Considering that the HCMA would be utilized in South China, where the annual lowest temperature rarely reaches $0{ }^{\circ} \mathrm{C}$, only high temperature performance was investigated in this study. The temperature sweep test, from which Superpave rutting factor and failure temperature could be derived, was conducted for the sake of high temperature performance evaluation. The temperature sweeping test started from $64^{\circ} \mathrm{C}$ and then the temperature would increase with a gap of $6^{\circ} \mathrm{C}$ till the detected rutting factor $\left(\mathrm{G}^{*} / \sin \delta\right)$ was below the low limit commanded in AASHTO M 320 [32], i.e., $1.0 \mathrm{kPa}$ for unaged bitumen samples and $2.2 \mathrm{kPa}$ for short-term-aged ones. Short-term-aged bitumen samples were prepared by rolling thin-film oven (RTFO) test according to AASHTO T 240 [33]. At first, heated to liquid state in advance, $(35 \pm 0.5) \mathrm{g}$ of asphalt binder was poured in a glass bottle. Then the bottle was placed in the rolling thin-film oven at $(163 \pm 0.5){ }^{\circ} \mathrm{C}$ for $85 \mathrm{~min}$. Binder after RTFO test is regarded as short-term-aged bitumen. Additionally, to simulate the repeated loading and unloading process of different vehicle loads on asphalt pavement, MSCR test was performed on the same short-term-aged bitumen sample that was previously used in the temperature sweep test, but a relaxation period of at least $1 \mathrm{~min}$ was required before its running, as described in AASHTO T 350 [34]. It needs to be declared that the highest temperature at which rutting factor was greater than $2.2 \mathrm{kPa}$ was regarded as the initial test temperature for MSCR test, in accordance with AASHTO M 332 [35]. The bitumen samples underwent creep and recovery cycles under two different stress levels, $0.1 \mathrm{kPa}$ and $3.2 \mathrm{kPa}$, respectively. A regular MSCR test consists of ten creep-recovery cycles at a stress level of $0.1 \mathrm{kPa}$ and immediately another ten cycles at $3.2 \mathrm{kPa}$. A single creep-recovery cycle comprises $1 \mathrm{~s}$ of loading period and then $9 \mathrm{~s}$ of rest period. Figure 3 shows the loading path of a standard MSCR sequence. Three related parameters, namely, the average percent recovery $(R \%)$, non-recoverable creep compliance $\left(J_{\mathrm{nr}}\right)$, and stress sensitivity parameter $\left(J_{\text {nr-diff }}\right)$, were recorded to appraise the high temperature property of test bitumen. Eventually, applicable traffic level for corresponding binder samples were classified.

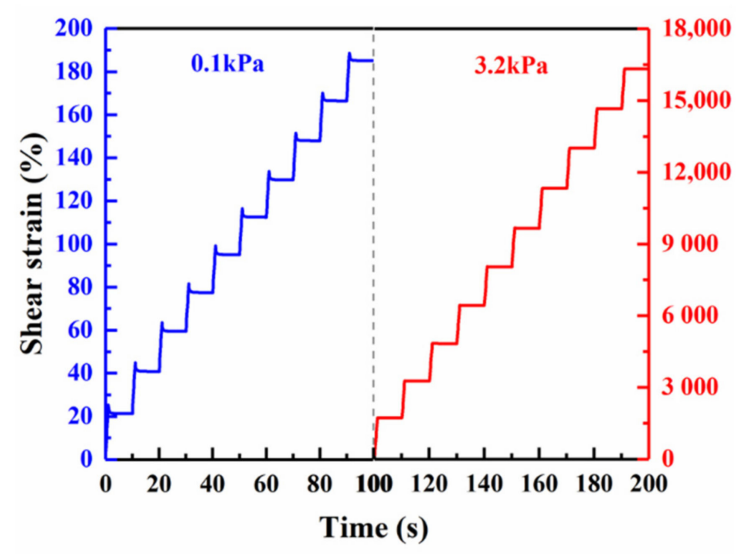

Figure 3. Diagram of multiple stress creep recovery (MSCR).

\subsubsection{Frequency Sweep Test}

Asphalt pavements are subjected to dynamic vehicle loads, the frequency of which would affect the viscoelastic properties of asphalt materials. The correlation between the dynamic mechanical properties of a material and test frequency at a specific temperature can be expressed in a specific function, known as the dynamic thermomechanical analysis (DMA) frequency spectrum. However, the DMA frequency spectrum whose frequency range spans multiple orders of magnitude could hardly be performed, limited by the instrument's test range. In order to overcome the limitations and obtain a master curve [36] spanning a broad frequency domain, a frequency sweep test can be employed to measure numerous frequency spectra under various temperatures over a narrow but constant frequency domain. Then, the time-temperature superposition principle was utilized to 
convert them to a master curve over a broad frequency domain at reference temperature $\left(40^{\circ} \mathrm{C}\right)$. In this study, the frequency sweep test was undertaken on HAMA and HBMA to characterize their holistic rheological properties. The frequency sweep test, frequency of whom ranged from 0.1 to $30 \mathrm{~Hz}$, was conducted from 4 to $76^{\circ} \mathrm{C}$, with an increment of $12{ }^{\circ} \mathrm{C}$. To ensure all strain during the test is within linear viscoelastic range, a strain level of $0.5 \%$ was set based on the result from amplitude sweep prior to being undertaken on the binder samples.

\subsubsection{Gel Permeation Chromatography (GPC)}

In order to unveil the interrelationship between hydrochar and binder fractions, the molecular weight distribution analysis was conducted through gel permeation chromatography (GPC) test [37]. An Agilent 1260 GPC was employed to categorize the components of different binders according to molecular size. Binder sample was prepared as diluent solution at a concentration of $1.0 \mu \mathrm{g} / \mathrm{mL}$ using tetrahydrofuran as solvent, and then was positioned into the injection module after pre-filtration through a $0.2 \mu \mathrm{m}$ syringe filter made of poly (tetra fluoroethylene). Column calibration was finished using a polystyrene solution, at a concentration of $1 \mathrm{mg} / \mathrm{mL}$ as calibration substance, $M_{\mathrm{W}}$ (weight-average molecular weight) of which was known. A calibration curve would be derived after the column calibration, which was intended to correspond retention time to $M_{\mathrm{w}}$. Two tandem chromatographic columns (PLgel $3 \mu \mathrm{m}$ Mixed-3 and PLgel $5 \mu \mathrm{m} 103 \AA$ ) were used for molecular separation. Within the procedure of the GPC test, the binder-THF solution was drained through chromatographic columns, maintained at $30{ }^{\circ} \mathrm{C}$ and controlled to flow at a rate of $1.0 \mathrm{~mL} / \mathrm{min}$ for $25 \mathrm{~min}$. The constituents' concentrations in the eluent were converted from original signal response recorded by a differential refractometer, with the calibration curve, and then the derivative GPC chromatograms were further converted into the molecular size distribution.

\subsubsection{Fourier-Transform Infrared Spectroscopy (FTIR)}

Known as a popular and reliable chemical method, Fourier-transform infrared spectroscopy (FTIR), was employed to identify the functional groups of the test samples, and to evaluate the anti-aging effect of hydrochar on asphalt [38]. In this study, the instrument used was Nicolet IS50 (Thermo Fisher Scientific, Waltham, MA, USA). The FTIR test mainly consists of the two following steps: (1) fabricating a pellet sample (around $1 \mathrm{~mm}$ thick) by adding $\mathrm{KBr}$ powder, and (2) subsequently exposing the sample to intermediate infrared ray ranging from 4000 to $500 \mathrm{~cm}^{-1}$ to obtain the infrared spectroscopy (recorded in transmittance). Thirty-two scans per spectrum were conducted with a resolution of $4 \mathrm{~cm}^{-1}$.

\section{Results and Discussion}

\subsection{Rheological Tests}

\subsubsection{Basic Characteristics}

In terms of examining the basic characteristics of asphalt binder, penetration, ductility and softening point are habitually included in researchers' laboratory plans due to accessibility. However, considering that the evenness induced by hydrochar modifiers may lead to premature brittle fracture, which consequently reduces the reliability of test results, the ductility test was excluded from the laboratory plan. Hence, only the other two tests were carried out, whose results are displayed in Figure 4. As apparent from the figure, both incorporation of HA and HB decreased the penetration value of Pen60/70, making the binder thicker. Compared to Pen60/70, the softening point values of HAMA and HBMA were mildly 5.2 and $3.2{ }^{\circ} \mathrm{C}$ higher, respectively. Figure 4 reveals that the HCMA binders generally exhibited more satisfactory performance at high service temperature. Not only that, the influence of HA on the empirical parameters was more noticeable than that of $\mathrm{HB}$. 


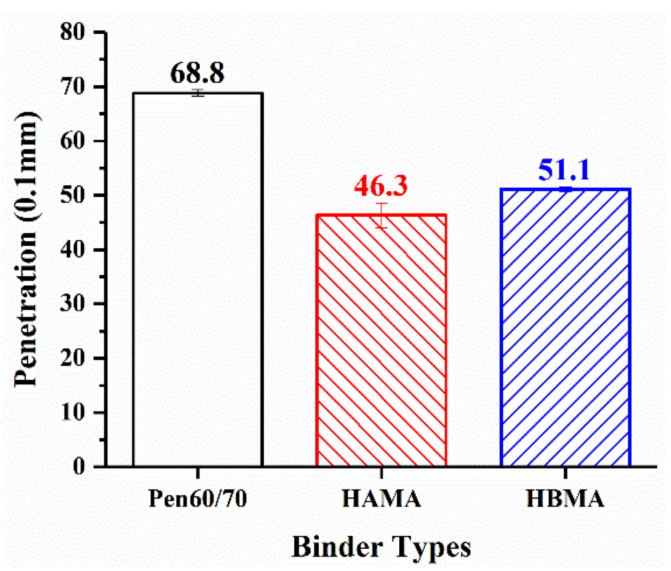

(a)

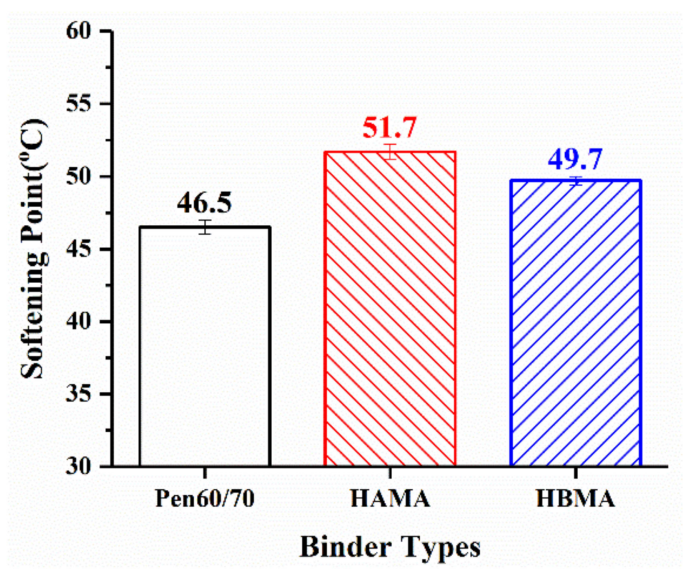

(b)

Figure 4. Conventional binder test results: (a) penetration and (b) softening point.

\subsubsection{Workability}

It has long been known that rotational viscosity of bitumen is a useful parameter to determinate the proper mixing and compaction temperature of asphalt mixtures. Figure 5 plots the dynamic viscosity of test binders at three different temperatures. In line with similar research [26], the addition of hydrochar modifiers slightly raised viscosity, causing an adverse impact on the workability. This phenomenon might be attributed to the stiffening effect of corn stalk fiber residues, which made the binder more viscous and consequently lowered its fluidity during mix production. The detrimental impact of HA on workability was more noticeable. As demonstrated in AASHTO specification [32], dynamic viscosity at $135^{\circ} \mathrm{C}$ must not exceed $3000 \mathrm{cP}$ for the purpose of guaranteeing that the asphalt mixture is properly blended and compacted at the designed void ratio. It is delightful to find out that both HAMA and HBMA conformed above requirement, indicating fairly sufficient workability of HCMA.

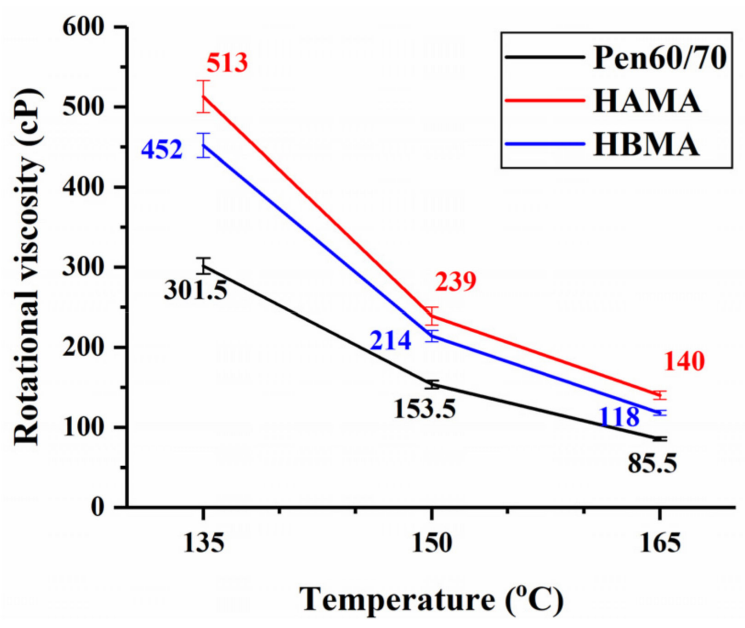

Figure 5. Rotational viscosity test results.

\subsubsection{Storage Stability}

Difference in softening point is a reliable indicator to evaluate the storage stability of asphalt binder. A requirement is specified in ASTM D 5892 [39] that the difference in softening points between the top and the bottom parts of qualified binder sample should not exceed $2.5^{\circ} \mathrm{C}$. Based on the results detailed in Figure 6, it was noted that HAMA showed a $19.0^{\circ} \mathrm{C}$ softening point difference, indicating the worst storage performance, followed by HBMA with $11.85^{\circ} \mathrm{C}$ while the base binder exhibited the best storage perfor- 
mance with only $0.2^{\circ} \mathrm{C}$. Better storage stability of HBMA could be ascribed to HB's more homogeneous distribution in asphalt binder. Both HAMA and HBMA failed to meet the requirement specified in ASTM D 5892 [39], which meant further modification was needed to improve the storage stability of HCMA before its widespread application in realistic pavement construction.

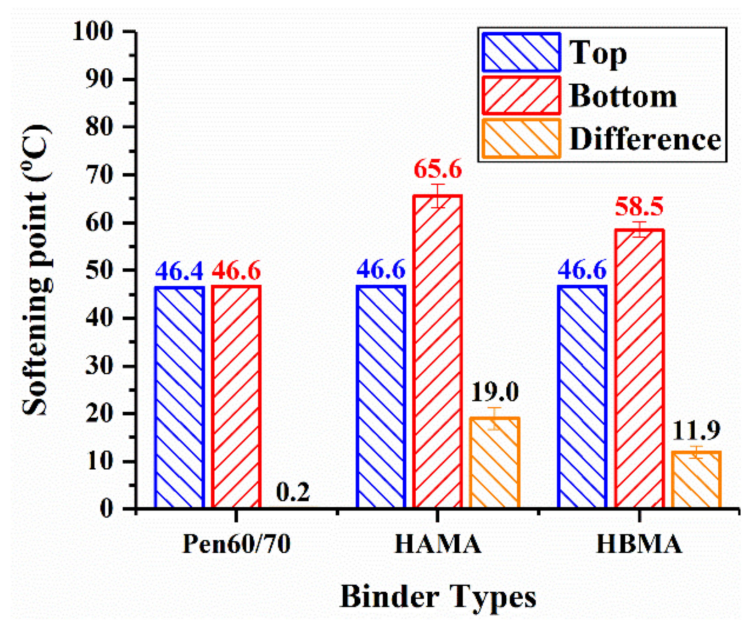

Figure 6. Storage stability test results.

\subsubsection{Rutting Resistance}

The high temperature performances of test binders were appraised by two DSR tests, namely the temperature sweep test and MSCR test. The correlation between $\mathrm{G}^{*} / \sin \delta$ and test temperature is displayed in Figure 7a,c. Moreover, the test results of failure temperature, at which $G^{*} / \sin \delta$ is equivalent to respective threshold for unaged specimens and short-term-aged ones are visible in Figure $7 \mathrm{~b}, \mathrm{~d}$. As can be seen from Figure $7 \mathrm{~b}, \mathrm{~d}$, hydrochar modifiers substantially heighten the failure temperature of base asphalt in both unaged and short-term-aged levels. As depicted in AASHTO specification [32], for unaged binder, Pen60/70 accorded with the provision of PG64, while HAMA and HBMA could be identified as PG76 and PG70. Similarly, for short-term-aged binder, Pen60/70, HAMA, and HBMA were identified as PG58, PG70, and PG64, respectively. If rutting factor was chosen as the only criterion, HAMA seemed to provide better enhanced high temperature performance (a whole PG grade) compared with HBMA.

However, when the asphalt binders were further evaluated by MSCR test, the difference of performance grade between HAMA and HBMA would be narrowed. Despite rutting factor can well assess the performance of base asphalt at high temperature, the reliability is reduced when modified asphalts are appraised only by rutting factor. As stated in AASHTO M 332 [35], extra criteria, including $J_{\mathrm{nr}}$ and $J_{\mathrm{nr} \text {-diff, }}$, need to be taken into consideration when performance grade is appraised in order to ensure that the test binder can exhibit good elastic behavior at standard traffic level. $J_{\mathrm{nr}}$ at $3.2 \mathrm{kPa}$ cannot be greater than $4.5 \mathrm{kPa}^{-1}$, for " $\mathrm{S}$ " grade, or $2.0 \mathrm{kPa}^{-1}$, for " $\mathrm{H}^{\prime}$ grade. The requirement of $J_{\mathrm{nr}}$ might lower the PG of test binder, which is presented in Figure 8a. The non-recoverable creep compliance $\left(J_{\mathrm{nr}}\right)$, recovery ratio $(R \%)$ and corresponding traffic level from the MSCR test are given in Table 2. It is remarkable that the $J_{\mathrm{nr}}$ of HAMA exceeds $4.5 \mathrm{kPa}^{-1}$ at $70{ }^{\circ} \mathrm{C}$ and meets the requirement at $64{ }^{\circ} \mathrm{C}$, hence, it should be identified as PG64 instead of PG70. Similarly, Pen60/70 and HBMA should be identified as PG58 and PG64, respectively. Both short-term-aged HAMA and HBMA achieve the same PG using MSCR test, which might be more reasonable. As detailed in Figure $8 \mathrm{~b}$, the unmodified bitumen displayed the higher $J_{\mathrm{nr}}$ value than that of HBMA at both stress levels at $58{ }^{\circ} \mathrm{C}$. Compared with Pen60/70 at $58{ }^{\circ} \mathrm{C}$, HBMA showed lower $J_{\mathrm{nr}}$ values, implying heightened rutting resistance, which cohered with previous test results in this study, softening point and Superpave rutting factor. Additionally, HAMA had smaller $J_{\mathrm{nr}}$ values than that of HBMA at $64^{\circ} \mathrm{C}$, which 
meant that enhanced rutting resistance was promoted by HA. The above inferences were consistent with their responding traffic level. Similarly, as detailed in Table 2, comparison of the $R \%$ results (Pen60/70 verse HBMA at $58{ }^{\circ} \mathrm{C}$ and HAMA verse HBMA at $64{ }^{\circ} \mathrm{C}$ ) verified that HCMA recovered more than base asphalt did within the rest period. The greater recovery ratio of HCMA supported the viewpoint that the addition of hydrochar leads to superior elastic behavior of asphalt, more deformations of which can be recovered.

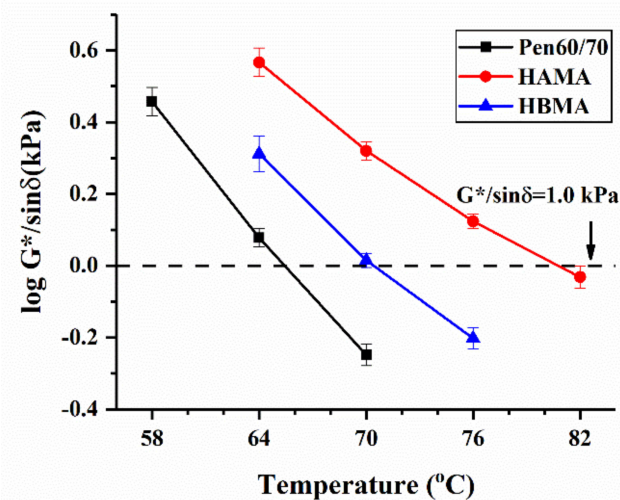

(a)

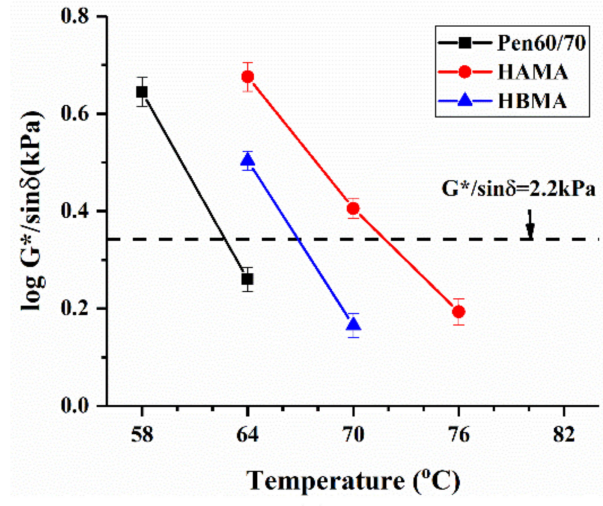

(c)

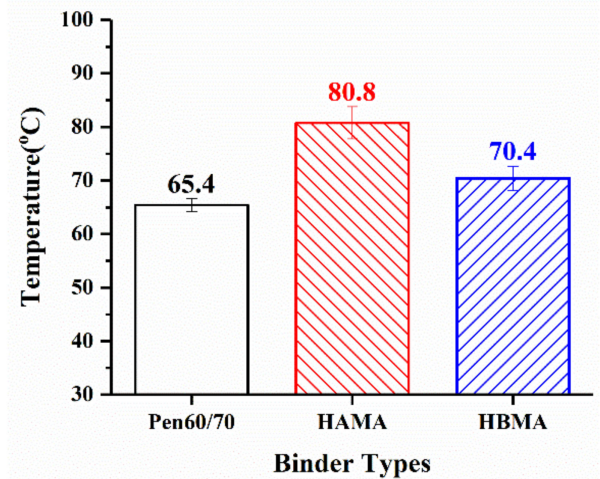

(b)

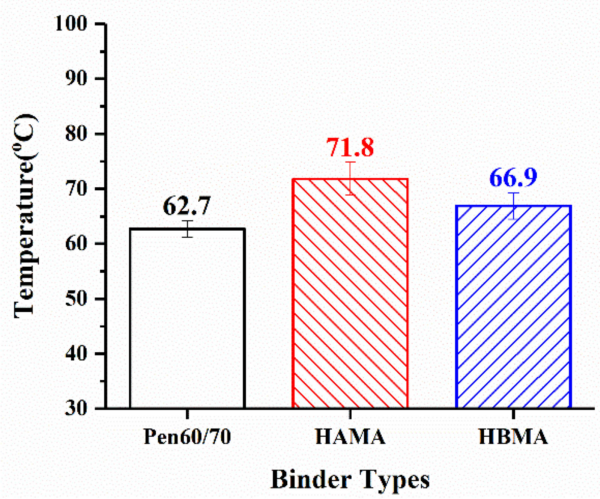

(d)

Figure 7. Temperature sweep test results: (a) rutting factor (unaged); (b) failure temperature (unaged); (c) rutting factor (short-term-aged); and (d) failure temperature (short-term-aged).

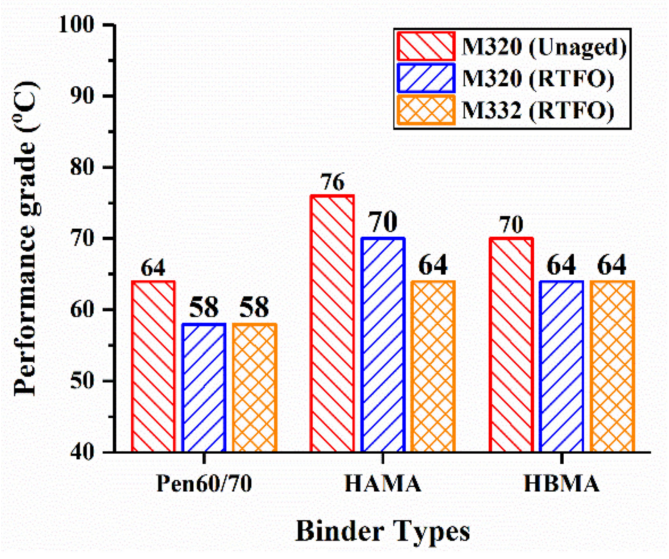

(a)

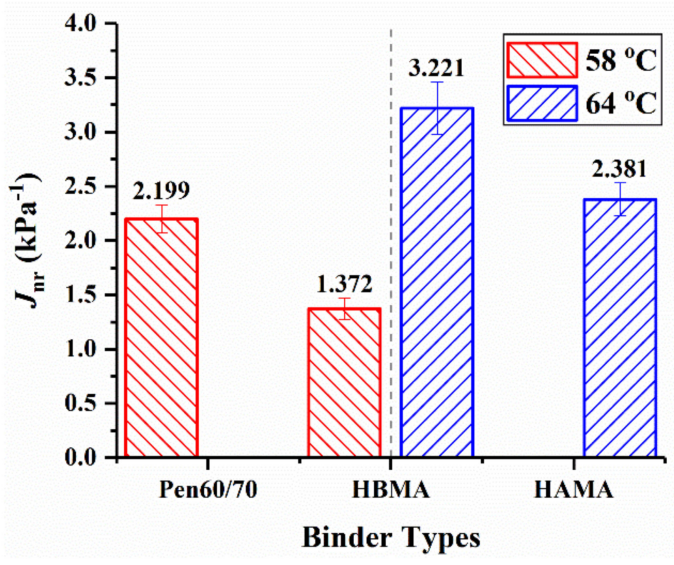

(b)

Figure 8. Comparison of MSCR results: (a) Performance grade and (b) $J_{\mathrm{nr}}$. 
Table 2. Multiple stress creep recovery (MSCR) test results.

\begin{tabular}{|c|c|c|c|c|c|c|c|}
\hline \multirow{2}{*}{ Binder Types } & \multirow{2}{*}{ Temperature $\left({ }^{\circ} \mathrm{C}\right)$} & \multicolumn{3}{|c|}{$J_{\mathrm{nr}}$} & \multicolumn{2}{|c|}{ Recovery (\%) } & \multirow{2}{*}{ Traffic Level } \\
\hline & & $0.1 \mathrm{kPa}$ & $3.2 \mathrm{kPa}$ & $J_{\text {nr-diff }}(\%)$ & $0.1 \mathrm{kPa}$ & $3.2 \mathrm{kPa}$ & \\
\hline Pen60/70 & 58 & 2.039 & 2.199 & 7.8 & 0.6 & -0.5 & “S" \\
\hline \multirow{2}{*}{ HAMA } & 64 & 1.881 & 2.381 & 26.6 & 8.7 & 1 & "S" \\
\hline & 70 & 1.771 & 5.034 & 184.3 & 17.9 & -0.5 & Failed $^{\mathrm{a}}$ \\
\hline \multirow{2}{*}{ HBMA } & 58 & 1.207 & 1.372 & 13.7 & 6.3 & 0 & "H" \\
\hline & 64 & 2.892 & 3.221 & 11.4 & 3.4 & -0.3 & "S" \\
\hline
\end{tabular}

a "Failed" means the responding binder wasn't qualified as any traffic level at responding temperature.

\subsubsection{Overall Rheological Behavior}

As elaborated in Section 2.2.5, the frequency sweep of binder sample was performed at various temperatures and frequencies. According to the time-temperature superposition principle, the procedure of developing the master curves of complex shear modulus $G^{*}$ at $40^{\circ} \mathrm{C}$ was expatiated by the following steps: Firstly, second-order polynomial form of the shift factor relationship (Equation (1)) was substituted into the general form of sigmoidal function (Equation (2) and then derived the final form Equation (3)); Secondly, nonlinear fitting, which consisted of 3000 iterations, was performed with Equation (3), to determine the six constants $\left(\delta, \alpha, \beta, \gamma a_{1}, a_{2}\right)$. Regression constants of the sigmoidal function and second-order polynomial are listed in Table 3 .

$$
\log f_{r}=\log f+a_{1}\left(T_{R}-T\right)+a_{2}\left(T_{R}-T\right)^{2}
$$

where $f_{r}$ refers to the reduced frequency at the reference temperature $T_{R}, a_{1}$ and $a_{2}$ correspond to model constants, while $f$ stands for the loading frequency at the test temperature $T$.

$$
\log \left(\mathrm{G}^{*}\right)=\delta+\frac{\alpha}{1+e^{\beta+\gamma \log \left(f_{r}\right)}}
$$

where $\beta, \gamma$ work as coefficients describing shape of the sigmoidal function, $\alpha$ and $\delta$ are respectively the upper and low limit of complex shear modulus $G^{*}$.

$$
\log \left(\mathrm{G}^{*}\right)=\delta+\frac{\alpha}{1+e^{\beta+\gamma\left[\log f+a_{1}\left(T_{R}-T\right)+a_{2}\left(T_{R}-T\right)^{2}\right]}}
$$

Table 3. Regression constants of the second-order polynomial and sigmoidal function.

\begin{tabular}{ccccc}
\hline \multicolumn{2}{c}{ Constants } & Pen60/70 & HAMA & HBMA \\
\hline Second-order & $a_{1}$ & 0.087129 & 0.0937799 & 0.0834853 \\
polynomial & $a_{2}$ & 0.000585222 & 0.000197275 & 0.000490108 \\
\hline & $\delta$ & -0.818071 & 4.55092 & 3.04264 \\
Sigmoidal & $\alpha$ & 9.78038 & 3.8313 & 5.47337 \\
Function & $\beta$ & -0.225198 & 1.72356 & 0.725259 \\
& $\gamma$ & -0.416557 & -0.977483 & -0.684152 \\
& $\mathrm{R}^{2} @\left|\mathrm{G}^{*}\right|$ & 0.999342 & 0.997296 & 0.99783 \\
\hline
\end{tabular}

Figure 9 plots the fitting result of investigated binders. Figure $9 \mathrm{a}$ is the scatters of transformed result data and Figure $9 \mathrm{~b}$ is the regression curves of sigmoidal model. As the above-mentioned principle of viscoelastic materials describes, modulus at low frequencies is equivalent to that at high temperatures and vice versa. It is also visible that the bitumen modified by hydrochar have evidently higher complex shear modulus than Pen60/70 at low frequencies, implying superior deformation resistance. At high frequencies, all binders had similar modulus, which meant neglectable impact of hydrochar on the low 
temperature characteristic of base bitumen. The above inferences analyzing master curves were in good agreement with results of MSCR tests.

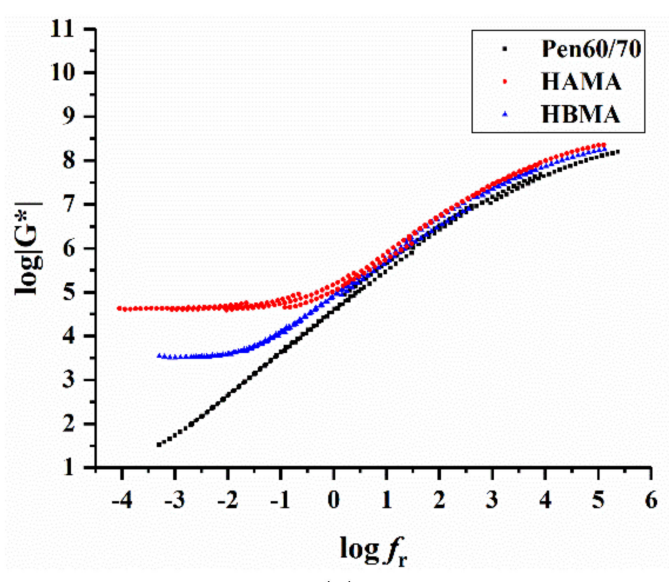

(a)

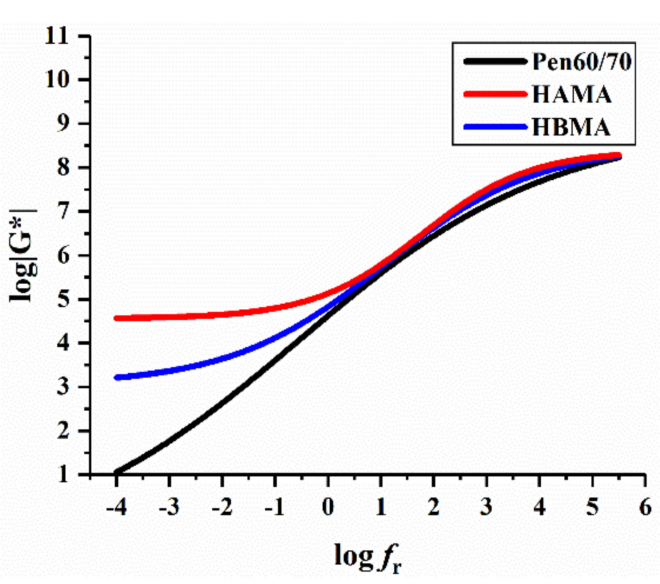

(b)

Figure 9. Master curves of test binders at $40^{\circ} \mathrm{C}$ : (a) scatters of transformed result data and (b) regression curves of sigmoidal model.

\subsection{Chemical Analysis}

\subsubsection{Molecular Weight Distribution}

Figure 10 presents the GPC chromatograms of the investigated binders. Referring to related studies concerning GPC analyzation, the components of bitumen can be discriminated as different groups by weight-average molecular weight $\left(M_{\mathrm{w}}\right)$ [37]. The chromatograms of target material are mainly concentrated on retention time from 11.0 to 17.8 min are presented in Figure 10, corresponding to $M_{\mathrm{w}}$ ranging from 18,647 to 134 based on the calibration curve mentioned in Section 2.2.6. Apparently, major peaks of all binders appear around $15.5 \mathrm{~min}$, and no additional peak is noticeable from neither the HAMA nor HBMA, which might be attributed to the low solubility of hydrochar or reaction products in THF. Those insoluble constituents were segregated by filtration, which meant they were not taken into account in the GPC analysis. Logically, the result obtained by GPC might have slightly less significance for molecular weight distribution analysis of HCMA, because the dissolved portion of HCMA could hardly represent the entirety. After all, some information still can be obtained by the chromatograms.

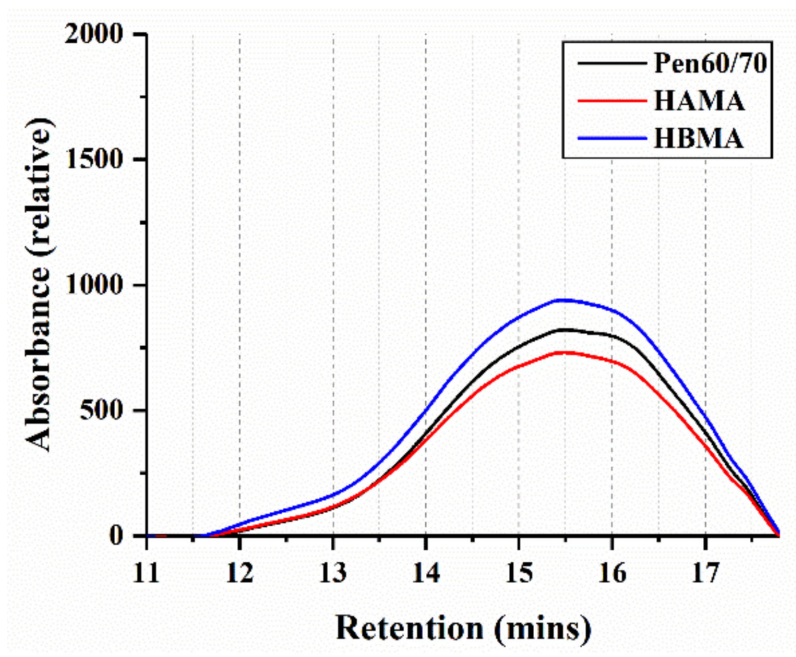

Figure 10. Gel permeation chromatography (GPC) chromatograms of test binders. 
Table 4 lists the results of the GPC test obtained by applying signal processing and definite integral analysis. In order to depict the molecular weight distribution of investigated binders, five indicators were chosen including the peak molecular weight $\left(M_{\mathrm{p}}\right)$, number-average molecular weight $\left(M_{\mathrm{n}}\right)$, weight-average molecular weight $\left(M_{\mathrm{w}}\right)$, z-average molecular weight $\left(M_{\mathrm{z}}\right)$ and dispersity $\left(\bigoplus=M_{\mathrm{w}} / M_{\mathrm{n}}\right)$. As observed in Figure 11a, $\mathrm{b}$, it is recognized that both molecular weight $\left(M_{\mathrm{w}}, M_{\mathrm{n}}\right)$ of HAMA and HBMA are apparently higher, compared with that of Pen 60/70. This difference could be attributed to the solubility of the hydrochar fraction in THF. The reaction products between hydrochar and base bitumen probably dissolve in THF, which increases the molecular weight.

Table 4. Molecular weight distribution.

\begin{tabular}{cccccc}
\hline Binder Types & $\boldsymbol{M}_{\mathbf{p}}(\mathbf{g} / \mathbf{m o l})$ & $\boldsymbol{M}_{\mathbf{n}}(\mathbf{g} / \mathbf{m o l})$ & $\boldsymbol{M}_{\mathbf{w}}(\mathbf{g} / \mathbf{m o l})$ & $\boldsymbol{M}_{\mathbf{z}}(\mathbf{g} / \mathbf{m o l})$ & $\boldsymbol{\oplus}(-)$ \\
\hline Pen60/70 & $641 \pm 19$ & $574 \pm 3$ & $1162 \pm 54$ & $2699 \pm 440$ & $2.0250 \pm 0.0960$ \\
HAMA & $698 \pm 17$ & $582 \pm 9$ & $1209 \pm 32$ & $2809 \pm 212$ & $2.0777 \pm 0.0281$ \\
HBMA & $729 \pm 16$ & $593 \pm 10$ & $1278 \pm 61$ & $3130 \pm 208$ & $2.1527 \pm 0.0688$ \\
\hline
\end{tabular}

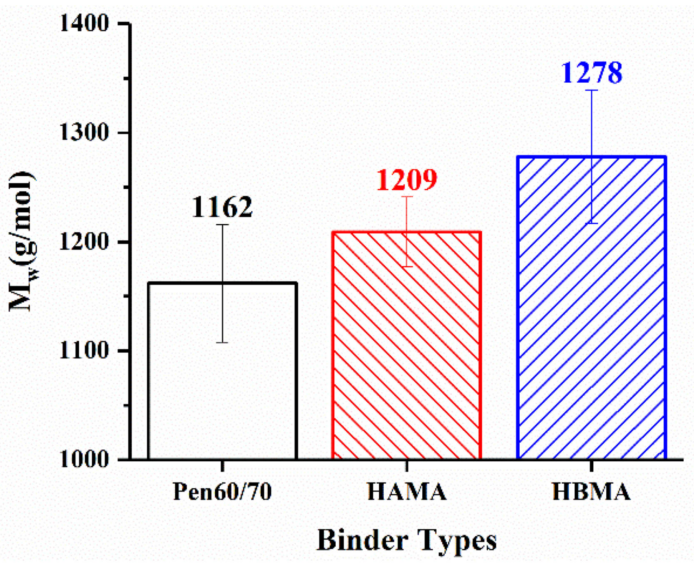

(a)

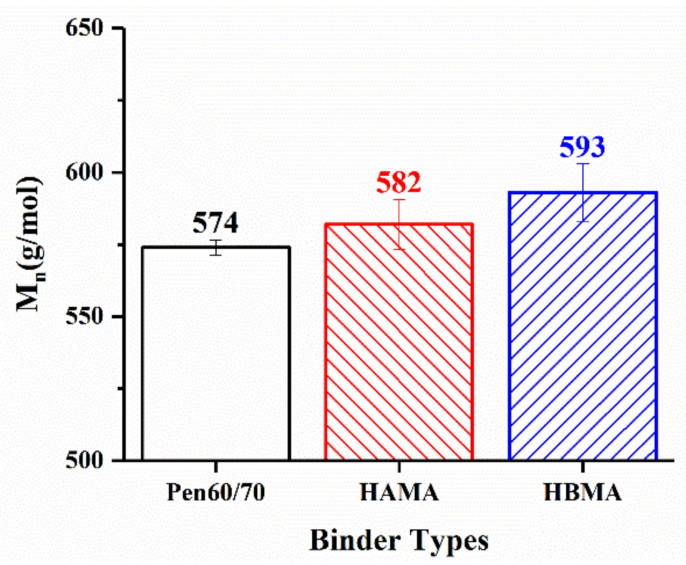

(b)

Figure 11. GPC result analysis: (a) weight-average molecular weight and (b) number-average molecular weight.

\subsubsection{Fourier-Transform Infrared Spectroscopy}

The generation of free radicals contributes most to asphalt aging. In other words, if the generation of free radicals can be inhibited or delayed, the aging process of binder would be remarkably hindered, which will consequently make contribution to the performance and longevity of asphalt pavement. Figure 12a-c exhibits the FTIR test result of base asphalt, HA and HB, separately. In Figure 12a, the bands at $2925 \mathrm{~cm}^{-1}$ can originate from asymmetric $\mathrm{C}-\mathrm{H}$ stretching vibration of methyl and methylene groups, while those at $2854 \mathrm{~cm}^{-1}$ from symmetric $\mathrm{C}-\mathrm{H}$ stretching vibration of methyl and methylene groups. As presented in Figure $12 b, c$, for both HA and HB, the major absorbance peaks at the 3437, 1632, 1459 and $1059 \mathrm{~cm}^{-1}$ are conspicuous. The absorbance band near $3437 \mathrm{~cm}^{-1}$ is concerned with the $\mathrm{N}-\mathrm{H}$ or $\mathrm{O}-\mathrm{H}$ stretching vibration of the amino groups and hydrogen-bonded hydroxyl groups, as that near $1632 \mathrm{~cm}^{-1}$ might be attributed to the $\mathrm{C}=\mathrm{O}$ stretching vibration of carbonyl groups. Besides, peaks around $1450 \mathrm{~cm}^{-1}$ might be related to $-\mathrm{CH} 2-$ scissor vibration of methylene groups, as those around $1059 \mathrm{~cm}^{-1}$ are induced by the stretching of $\mathrm{C}-\mathrm{O}$ and $\mathrm{S}=\mathrm{O}$. As can be clearly seen in Figure $12 \mathrm{a}, \mathrm{d}, \mathrm{e}$, the functional group compositions of HAMA and HBMA are comparable to Pen 60/70, except some peak areas being slightly different. As shown in Figure 12b-e, the peaks of HAMA and HBMA near $3437 \mathrm{~cm}^{-1}$ are significant compared to $\mathrm{HA}$ and $\mathrm{HB}$, probably due to chemical reaction between hydrochar and bitumen faction. It is distinct that HAMA and HBMA have analogous major bands, but the peak areas differ greatly around $1030 \mathrm{~cm}^{-1}$ and $810 \mathrm{~cm}^{-1}$. This distinction may 
be ascribed to the discrepancies in the extent of dissolution and reaction of HA and $\mathrm{HB}$ in bitumen fractions.

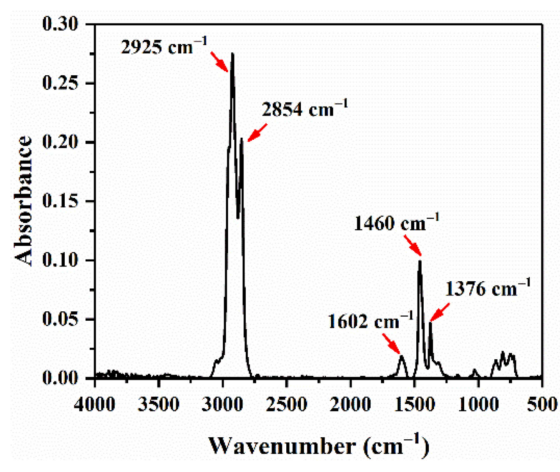

(a)

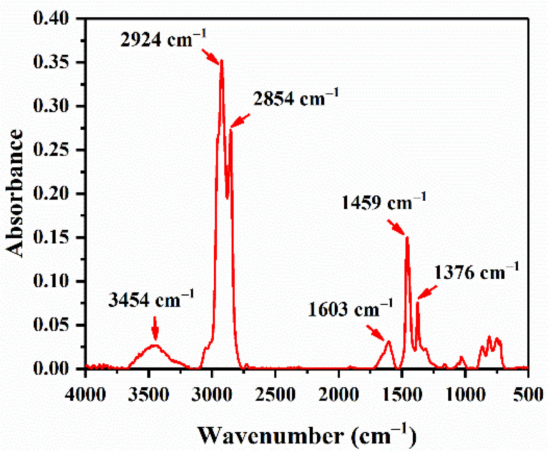

(d)

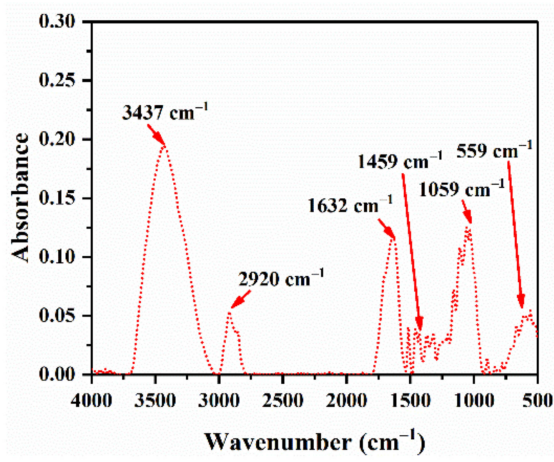

(b)

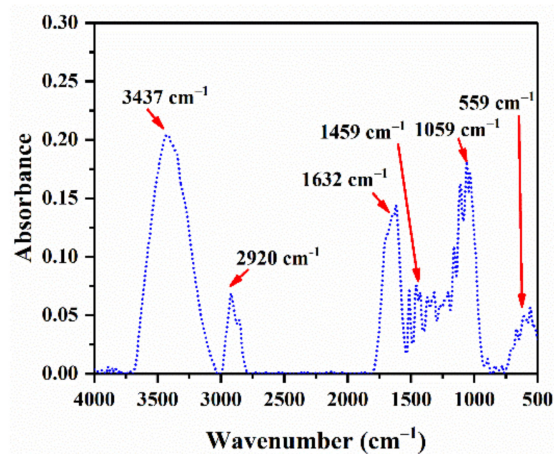

(c)

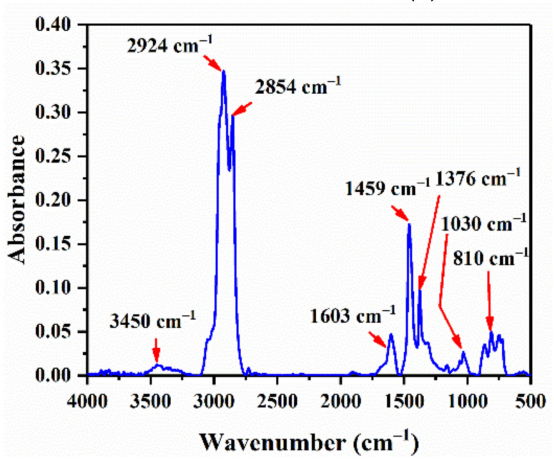

(e)

Figure 12. Fourier-transform infrared spectroscopy (FTIR) test results: (a) base asphalt; (b) HA; (c) HB; (d) HAMA; and (e) HBMA.

Curve-fitting analysis is a very effective method for competently separating FTIR overlapping peaks to obtain each absorption peak area, which improves the accuracy of quantitative evaluation. The software PeakFit (V4.12, Systat Software, San Jose, CA, USA) was employed to perform the numerical fitting. Before fitting, FTIR spectra was smoothed by signal processing. Figure 13 illustrates the process of smoothed signal and fitted peak curves. In accordance with previous studies [38] applying this method, carbonyl index $I_{\mathrm{C}}=\mathrm{O}$ was calculated for unaged binder samples and RTFO aged ones, while derived index ratio of aging $\left(R_{\mathrm{A}}\right)$ was also recorded, as presented in Table 5 . $I_{\mathrm{C}=\mathrm{O}}$ and $R_{\mathrm{A}}$ were obtained by Equations (4) and (5), respectively.

$$
\begin{gathered}
I_{\mathrm{C}=\mathrm{O}}=\frac{\text { Area the of carbonyl peak centered around } 1700 \mathrm{~cm}^{-1}}{\sum \text { Area of the spectral fitted peaks between } 2000 \text { and } 600 \mathrm{~cm}^{-1}} \\
R_{\mathrm{A}}=\frac{I_{\mathrm{C}=\mathrm{O}} \text { of } \mathrm{RFTO} \text { binder }}{I_{\mathrm{C}=\mathrm{O}} \text { of unaged binder }}
\end{gathered}
$$

\begin{tabular}{|c|c|c|c|}
\hline \multirow{2}{*}{ Binder Types } & \multicolumn{2}{|c|}{$I_{\mathrm{C}=\mathrm{O}}$} & \multirow{2}{*}{$R_{\mathrm{A}}$} \\
\hline & Unaged Binder & RFTO Binder & \\
\hline Pen60/70 & 0.0364 & 0.0816 & 2.242 \\
\hline HAMA & 0.0510 & 0.1013 & 1.986 \\
\hline HBMA & 0.0586 & 0.0917 & 1.565 \\
\hline
\end{tabular}

Table 5. Result of FTIR quantitative evaluation. 


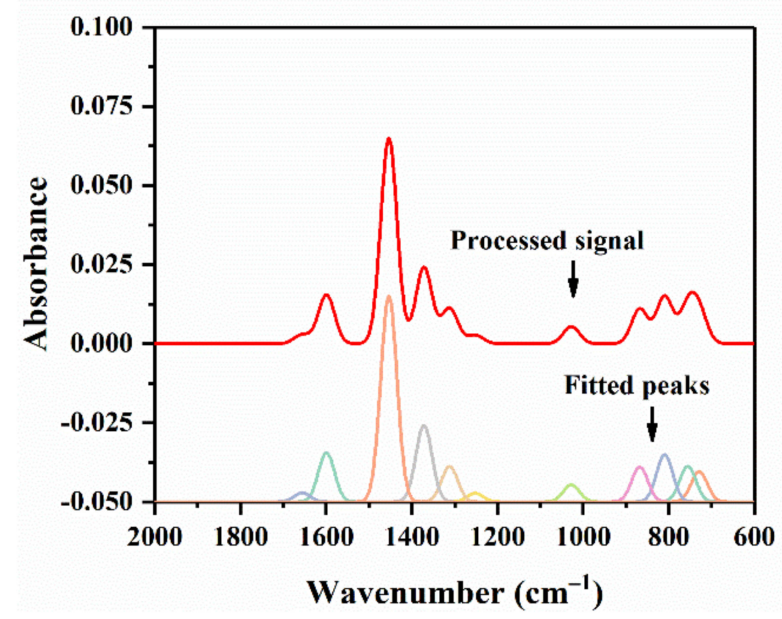

Figure 13. Curve-fitting analysis of FTIR for quantitative evaluation.

It can be seen that both HAMA and HBMA have bigger initial $I_{\mathrm{C}=\mathrm{O}}$ than base asphalt due to the incorporation of hydrochar modifiers, which contains carbonyl groups. However, after short-term aging, HAMA and HBMA show lower $R_{\mathrm{A}}$, which means hydrochar modifiers might prevent the oxidation of asphalt binder. Assumption was made that there would be steric hindrance phenol component in hydrochar preventing reaction between free radicals and oxygen, according to related study about lignocellulosic biomass [40]. Based on the hypothesis, more steric hindrance phenol component in HBMA than that in HAMA could be the explanation of why HBMA has a better anti-aging effect. Further confirmation of steric hindrance phenol in hydrochar should be followed. Inference could be drawn that hydrochar modifiers had convincing competence to impede the aging of asphalt binder.

\section{Conclusions}

This study presented a comprehensive investigation to explore the potential of utilizing hydrochar, a sort of innovative material produced from corn stalks as an environmentfriendly performance improver for asphalt binder. An experimental plan consisting of rheological and chemical tests was carried out on hydrochar and asphalt binder modified with hydrochar modifiers, as well. The following discoveries can be acquired based on the limited test results:

1. Two kinds of hydrochar (HA, HB) were produced by an innovative method called hydrothermal carbonization. The process involves accessible reaction material, corn stalks and water, without producing hazardous by-products, which is very simple but efficient. Thanks to the above advantages, it is of great possibility that the process can be implemented on an industrial scale.

2. Interrelationship between hydrochar and asphalt binder is discovered. The tiny fiber structures of hydrochar work as a kind of reinforced skeletons within the asphalt binder, which intensify the elastic behavior, the essence of mechanical performance.

3. Hydrochar inevitably has a detrimental impact on the workability of bitumen. This phenomenon might be attributed to the stiffening effect of corn stalk fiber residues, which made the binder more viscous and consequently lower its fluidity during mix production. After all, hydrochar-modified asphalt satisfies the viscosity requirement for construction.

4. HCMA has unsatisfying storage stability exceeding the requirement in ASTM D 5892, which reveals the heterogeneous distribution of hydrochar in asphalt binder during storing.

5. The integration of hydrochar and asphalt binder presents improved performance of asphalt binder at high temperatures, which can be proved by a great deal of criteria 
including lower penetration, higher softening point, bigger rutting factor, lower non-recoverable creep compliance, etc.

6. The better anti-aging effect contributed by Hydrochar modifiers is observed clearly using quantitative analysis on the FTIR spectra of unaged and RTFO-aged binders.

7. Higher reaction temperatures make hydrochar's particles smaller and more homogeneous, which results in slightly lower enhanced high temperature performance, more satisfying workability, better storage stability, and a greater anti-aging effect of hydrochar-modified asphalt.

Overall, this study ascertains the significant profit of employing corn-stalk-based hydrochar as an eco-friendly performance enhancer for petroleum binder in the pavement industry. After investigation, hydrothermal carbonization was recognized as an advisable solution for waste corn stalks for its environmental and economic benefits. Further exploration of methods, such as addition of bio-based reinforcing filler, to improve HACA's storage stability is urgent. Then, future study including real-scale corroboration on trial section and life cycle assessment of asphalt pavement with hydrochar modifiers will follow.

Author Contributions: Data curation, X.W.; Funding acquisition, C.H.; Investigation, C.H. and X.W.; Methodology, C.H.; Supervision, C.H.; Writing—original draft, X.W.; Writing—review \& editing, C.H. Both authors have read and agreed to the published version of the manuscript.

Funding: This research was funded by Canton-Hong Kong Joint Research Program (2019A0503004), and Fundamental Research Funds for the Central Universities. The APC funded by Pearl River S\&T Nova Program of Guangzhou is greatly acknowledged.

Institutional Review Board Statement: Not applicable.

Informed Consent Statement: Not applicable.

Data Availability Statement: The data used to support the findings of this study are available from the corresponding author upon request.

Acknowledgments: All the laboratory experiments were performed in the laboratory of South China University of Technology.

Conflicts of Interest: The authors declare no conflict of interest.

\section{References}

1. Chen, Z.; Chen, Z.; Yi, J.; Feng, D. Preparation method of corn stalk fiber material and its performance investigation in asphalt concrete. Sustainability 2019, 11, 4050. [CrossRef]

2. Lu, W.; Liu, R.H.; Chen, S.; Cai, W.F.; Tao, Y.W.; Yin, R.Z.; Mei, Y.F. Classification and comparison of physical and chemical properties of corn stalk from three regions in china. Int. J. Agric. Biol. Eng. 2014, 7, 98-106.

3. Li, C.; Zhang, J.; Dou, S.; Ren, Z. Dynamic change in amounts soil humic and fulvic acid during corn stalk decomposition. J. Jilin Agric. Univ. 2009, 31, 729-732.

4. Wang, S.; Dai, G.; Yang, H.; Luo, Z. Lignocellulosic biomass pyrolysis mechanism: A state-of-the-art review. Prog. Energy Combust. Sci. 2017, 62, 33-86. [CrossRef]

5. Zhu, X.; Liu, Y.; Qian, F.; Zhou, C.; Zhang, S.; Chen, J. Role of hydrochar properties on the porosity of hydrochar-based porous carbon for their sustainable application. ACS Sustain. Chem. Eng. 2015, 3, 833-840. [CrossRef]

6. Li, J.; Han, M.; Muhammad, Y.; Liu, Y.; Su, Z.; Yang, J.; Yang, S.; Duan, S. Preparation and properties of SBS-g-GOs-modified asphalt based on a thiol-ene click reaction in a bituminous environment. Polymers 2018, 10, 1264. [CrossRef]

7. Dhasmana, H.; Ozer, H.; Al-Qadi, I.L.; Zhang, Y.; Schideman, L.; Sharma, B.K.; Chen, W.; Minarick, M.J.; Zhang, P. Rheological and chemical characterization of biobinders from different biomass resources. Transp. Res. Rec. 2016, 2505, 121-129. [CrossRef]

8. Fini, E.H.; Kalberer, E.W.; Shahbazi, A.; Basti, M.; You, Z.; Ozer, H.; Aurangzeb, Q. Chemical characterization of biobinder from swine manure: Sustainable modifier for asphalt binder. J. Mater. Civ. Eng. 2011, 23, 1506-1513. [CrossRef]

9. Yang, X.; Mills-Beale, J.; You, Z. Chemical characterization and oxidative aging of bio-asphalt and its compatibility with petroleum asphalt. J. Clean Prod. 2017, 142, 1837-1847. [CrossRef]

10. Walters, R.C.; Fini, E.H.; Abu-Lebdeh, T. Enhancing asphalt rheological behavior and aging susceptibility using bio-char and nano-clay. Am. J. Eng. Appl. Sci. 2014, 7, 66-76. [CrossRef]

11. Zhao, S.; Huang, B.; Shu, X.; Ye, P. Laboratory investigation of biochar-modified asphalt mixture. Transp. Res. Rec. 2014, 2445, 56-63. [CrossRef] 
12. Zhao, S.; Huang, B.; Ye, X.P.; Shu, X.; Jia, X. Utilizing bio-char as a bio-modifier for asphalt cement: A sustainable application of bio-fuel by-product. Fuel 2014, 133, 52-62. [CrossRef]

13. Zhang, R.; Dai, Q.; You, Z.; Wang, H.; Peng, C. Rheological performance of bio-char modified asphalt with different particle sizes. Appl. Sci. 2018, 8, 1665. [CrossRef]

14. Zhou, X.; Adhikari, S. Flow-induced crystallization of biochar in bio-asphalt under various aging conditions. Sci. Total Environ. 2019, 695, 133943. [CrossRef]

15. Araúj, F.; Silva, I.S.V.; Pasquini, D. Application of polyester derived from biomass in petroleum asphalt cement. Polimeros 2017, 27, 136-140. [CrossRef]

16. Melotti, R.; Santagata, E.; Bassani, M.; Salvo, M.; Rizzo, S. A preliminary investigation into the physical and chemical properties of biomass ashes used as aggregate fillers for bituminous mixtures. Waste Manag. 2013, 33, 1906-1917. [CrossRef]

17. Tahami, S.A.; Arabani, M.; Mirhosseini, A.F. Usage of two biomass ashes as filler in hot mix asphalt. Constr. Build. Mater. 2018, 170, 547-556. [CrossRef]

18. Boura, S.A.; Hesami, S. Laboratory evaluation of the performance of asphalt mixtures containing biomass fillers. Road Mater. Pavement Des. 2020, 21, 2040-2053. [CrossRef]

19. Nahi, M.H.; Kamaruddin, I.B.; Madzlan, N. The Utilization of Rice Husks Powder as an Antioxidant in Asphalt Binder. Appl. Mech. Mater. 2014, 567, 539-544. [CrossRef]

20. Xue, Y.; Wu, S.; Cai, J.; Zhou, M.; Zha, J. Effects of two biomass ashes on asphalt binder: Dynamic shear rheological characteristic analysis. Constr. Build. Mater. 2014, 56, 7-15. [CrossRef]

21. Chen, Z.; Yi, J.; Chen, Z.; Feng, D. Properties of asphalt binder modified by corn stalk fiber. Constr. Build. Mater. 2019, 212, 225-235. [CrossRef]

22. Liu, F.; Yu, R.; Ji, X.; Guo, M. Hydrothermal carbonization of holocellulose into hydrochar: Structural, chemical characteristics, and combustion behavior. Bioresour. Technol. 2018, 263, 508-516. [CrossRef]

23. Park, K.Y.; Lee, K.; Kim, D. Characterized hydrochar of algal biomass for producing solid fuel through hydrothermal carbonization. Bioresour. Technol. 2018, 258, 119-124. [CrossRef] [PubMed]

24. Bao, D.; Yu, Y.; Zhao, Q. Evaluation of the chemical composition and rheological properties of bio-asphalt from different biomass sources. Road Mater. Pavement Des. 2019, 21, 1829-1843. [CrossRef]

25. Dong, Z.; Zhou, T.; Luan, H.; Wang, H.; Xie, N.; Xiao, G. Performance evaluation of bio-based asphalt and effects of physical and chemical modification. Road Mater. Pavement Des. 2018, 21, 1470-1489. [CrossRef]

26. Hu, C.; Feng, J.; Zhou, N.; Zhu, J.; Zhang, S. Hydrochar from corn stalk used as bio-asphalt modifier: High-temperature performance improvement and environmental impact. Environ. Res. 2021, 193, 110157. [CrossRef] [PubMed]

27. American Association of State and Highway Transportation Officials. Standard Method of Test for Penetration of Bituminous Materials. In AASHTO T 49; American Association of State and Highway Transportation Officials: Washington, DC, USA, 2015.

28. American Association of State and Highway Transportation Officials. Standard Method of Test for Softening Point of Bitumen (Ring-and-Ball Apparatus). In AASHTO T 53; American Association of State and Highway Transportation Officials: Washington, DC, USA, 2009.

29. American Association of State and Highway Transportation Officials. Standard Method of Test for Viscosity Determination of Asphalt Binder Using Rotational Viscometer. In AASHTO T 316; American Association of State and Highway Transportation Officials: Washington, DC, USA, 2019.

30. American Society for Testing and Materials. Standard Practice for Determining the Separation Tendency of Polymer from Polymer-Modified Asphalt. In ASTM D 7173; American Society for Testing and Materials: West Conshohocken, PA, USA, 2020.

31. American Association of State and Highway Transportation Officials. Standard Method of Test for Determining the Rheological Properties of Asphalt Binder Using a Dynamic Shear Rheometer (DSR). In AASHTO T 315; American Association of State and Highway Transportation Officials: Washington, DC, USA, 2020.

32. American Association of State and Highway Transportation Officials. Standard Specification for Performance-Graded Asphalt Binder. In AASHTO M 320; American Association of State and Highway Transportation Officials: Washington, DC, USA, 2017.

33. American Association of State and Highway Transportation Officials. Standard Method of Test for Effect of Heat and Air on a Moving Film of Asphalt Binder (Rolling Thin-Film Oven Test). In AASHTO T 240; American Association of State and Highway Transportation Officials: Washington, DC, USA, 2013.

34. American Association of State and Highway Transportation Officials. Standard Method of Test for Multiple Stress Creep Recovery (MSCR) Test of Asphalt Binder Using a Dynamic Shear Rheometer (DSR). In AASHTO T 350; American Association of State and Highway Transportation Officials: Washington, DC, USA, 2019.

35. American Association of State and Highway Transportation Officials. Standard Specification for Performance-Graded Asphalt Binder Using Multiple Stress Creep Recovery (MSCR) Test. In AASHTO M 332; American Association of State and Highway Transportation Officials: Washington, DC, USA, 2020.

36. American Association of State and Highway Transportation Officials. Standard Practice for Developing Dynamic Modulus Master Curves for Asphalt Mixtures. In AASHTO R 62; American Association of State and Highway Transportation Officials: Washington, DC, USA, 2013.

37. Lee, S.J.; Amirkhanian, S.N.; Shatanawi, K.; Kim, K.W. Short-term aging characterization of asphalt binders using gel permeation chromatography and selected Superpave binder tests. Constr. Build. Mater. 2008, 22, 2220-2227. [CrossRef] 
38. Wu, S.; Pang, L.; Mo, L.; Chen, Y.; Zhu, G. Influence of aging on the evolution of structure, morphology and rheology of base and SBS modified bitumen. Constr. Build. Mater. 2009, 23, 1005-1010. [CrossRef]

39. American Society for Testing and Materials. Standard specification for type IV polymer-modified asphalt cement for Use in pavement construction. In ASTM D 5892; American Society for Testing and Materials: West Conshohocken, PA, USA, 2000.

40. Kai, D.; Zhang, K.; Jiang, L.; Wong, H.Z.; Li, Z.; Zhang, Z. Sustainable and antioxidant lignin-polyester copolymers and nanofibers for potential healthcare applications. ACS Sustain. Chem. Eng. 2017, 5, 6016-6025. [CrossRef] 